DOI: 10.2478/linpo-2014-0010

\author{
A R T I C L E S
}

\title{
Nominal KAD form in Basse Mandinka: Its cognitive mapping and taxonomical status (Part 2)
}

\author{
Alexander Andrason \\ University of Stellenbosch, South Africa, aleksand@hi.is
}

\begin{abstract}
Alexander Andrason. Nominal KAD form in Basse Mandinka: Its cognitive mapping and taxonomical status (Part 2). The Poznan Society for the Advancement of the Arts and Sciences. PL ISSN 0079-4740, ISBN 978-83-7654-388-8, pp. 7-18

Purpose: The present study, divided into a series of two papers, provides a detailed empirical description and cognitive-grammaticalization analysis of the meaning of a Mandinka verbal expression compounded of the non-verbal predicator be 'be', a verbal noun expressing a given action and the postposition kay 'on, at' (so-called the Nominal KAD form).

Method: The author follows the cognitive approach to verbal semantics which consists first of determining the exact range of contextually induced senses and next of unifying such values into a consistent map based upon certain diachronic universals or grammaticalization paths.

Results: The synchronic inventory of senses of the Nominal KAD form (i.e. progressive, continuous, progressive-iterative, iterative, habitual and durative values) shows that this construction can be mapped using the imperfective path as a template of chaining. This mapping, hypothesized on the ground of synchronic semantic evidence and typological diachronic laws, is next corroborated by the structural properties of the Nominal KAD locution, especially by its locative and nominal character.

Conclusion: All the evidence enables the author to semantically define the NomKAD form as a nonadvanced imperfective-path gram.

Part 1: In the second article of the series, the author designs the map of the semantic potential of the Nominal KAD locution and corroborates it by analyzing formal properties of this construction.
\end{abstract}

Keywords: Baasse Mandinka, nominal KAD form, grammaticalization

\section{Introduction - the point where we left our discussion}

In accordance with our research scheme, in the first - previously published - article of the series of two, we offered a meticulous review of all the contextually induced senses (related to the domains of taxis, aspect and time) which are conveyed by the NomKAD form in Basse Mandinka. This detailed empirical study enabled us to determine the precise range of the semantic potential of this construction.

More specifically, the inventory of values carried out by the NomKAD form shows that although a progressive and ongoing sense predominates, the construction may not be 
equaled with an invariant expression of progressive and ongoing actions: the NomKAD locution is yet sometimes employed with the force of a continuous gram (especially with certain situational predicates such as siinoo 'sleep' or loo 'stand'), iterative gram, and even habitual gram. Furthermore, although it is usually confined to present and past reference frames, it may, under very particular circumstances (ni and ko clauses), refer to the future. Additionally, it offers uses that are problematically classifiable within the standard taxonomical classes. Namely, the NomKAD form quite commonly expresses repetitive progressive actions (in this use the form portrays the iteration as a collection of progressive events) - a semantic domain where the ideas of progressivity and iterativity meet (cf. the iterativeprogressive sense). Moreover, it can denote situations or activities that have been occurring since a determined point in the past to the present moment (the sense of a present or past inclusive perfect). We also observed that adjectival, cognition and emotion verbs regularly receive a transitory-ingressive reading in the NomKAD form - activities conveyed by these verbal roots are portrayed in a dynamic manner as processes of acquisition of qualities.

In accordance with the cognitive understanding of verbal semantics, this inventory of senses constitutes a basis for designing a model of the meaning of the form. Following our research strategy, in this paper, we will order the contextual diversity of values, determined in the previous article. That is to say, we will provide a unification of all the components of the semantic potential offered by the NomKAD construction, by modeling it into a consistent whole by means of one of the universal paths (cf. section 2). After that, we will corroborate the posited map by analyzing the form (i.e. structural and morphosyntactic properties) of the construction (cf. section 3.1) and verifying its cognitive compatibility with the hypothesized path mapping (cf. section 3.2). Finally, main conclusions will be drawn and a plan of future study designed (cf. section 4).

\section{Positing the map}

All different senses conveyed by the NomKAD - as far as aspectual, taxis and temporal properties are involved - including those that resist a straightforward categorization in a prototypical taxonomical class, can be grasped in their totality and explained as manifestations of the imperfective path. Put differently, one may match the values, which are offered by the NomKAD form, with portions of a universal evolutionary template, referred to as an imperfective path - a cline that governs the grammatical life of imperfective aspects and present tenses (cf. Bybee et al. 1994).

The imperfective cline establishes that constructions which typically function as imperfective aspects (or which provide some values characteristic of such imperfective aspects) tend to originate in locutions that express a continuative sense (the gram conveys the idea of keeping on doing something on one occasion) or an iterative sense (the gram introduces events that are repeated on more than one occasion). Subsequently, on the one hand, a continuative expression acquires the value of a progressive (it indicates ongoing dynamic activities) and continuous (it denotes ongoing situations - a situation is understood as presently enduring and the form is acceptable with non-dynamic and stative verbs, preserving their non-dynamic sense; cf. Bybee et al. 1994: 317). On the other hand, an iterative develops a habitual value (it expresses activities which are recurrent on numerous occasions so that they constitute a con- 
stant habit or customary phenomenon). After that, the two types of constructions may amalgamate and jointly, functioning as a broad imperfective present, acquire a gnomic sense. When aspectual nuances of progressivity and continuity are lost or weakened, the formation obtains the status of a general present tense (Bybee et al. 1994: 125-175; Haspelmath 1998: 41-45). ${ }^{1}$ One should observe that the path model posited by Bybee, Perkins \& Pagliuca typically concerns reduplicative inputs (Bybee et al. 1994: 125-75). Other types of inputs may undergo a marginally divergent development. In such cases, constructions which are born as progressive formations regularly expand to continuous uses. Afterwards, they become compatible with iterative and habitual domains and subsequently with gnomic uses (cf. Marchese 1986; Bybee et al. 1994: 135, 140-144; Haspelmath 1998; Bertinetto \& Lenci 2010: 39). Additionally, it should be noted that the imperfective path may also take place within a past time frame. In such instances, original progressive formations acquire senses in the order established previously, passing by the stages of a continuous, iterative and habitual past. In addition to that, they may also include another phase where an imperfective past (with all or some of its senses of progressivity, continuity, iterativity and habituality) acquires a non-imperfective (e.g. perfective, punctual, global and bounded) value. Consequently, a previously imperfective past is able to introduce both imperfective and perfective actions and activities - it turns into a simple past (Comrie 1976). ${ }^{2}$ The entire classical (simplified and abstract) model of the imperfective path may be schematically represented as follows:

\section{PROGRESSIVE $\rightarrow$ CONTINUOUS $\rightarrow$ ITERATIVE $\rightarrow$ HABITUAL $\rightarrow$ GNOMIC}

Figure 1: Imperfective path from progressive inputs in the present time frame

The Basse Mandinka data indicates that the semantic potential of the NomKAD corresponds to non-advanced sections of the imperfective cline, typically located in the present and past time frames. As mentioned and illustrated previously (cf. the first article in the series), if the reference time is present, the form predominantly expresses present progressive actions - this holds for dynamic, static and adjectival roots (the two latter classes of verbs typically acquire a dynamic ingressive reading). This dynamic progressive value clearly matches the initial stage of the imperfective path. With some non-dynamic situational verbs, however, the locution tends to denote continuous activities. This continuous sense reflects a second phase on the imperfective trajectory. In both cases - i.e. when employed as a progressive or continuous category - the NomKAD introduces ongoing processes or activities. Nevertheless, the locution also quite regularly introduces progressive and continuous activities that are repeated forming a frequentative collection of individual events and situations. If our evidence is correct and the line of semantic modifications predicted by the imperfective cline accurate, this

1 Such general present tenses are typically referred to as 'simple' (cf. Simple Present in English). However, in order to avoid the confusion with an identical notion which is used in order to denote certain past tenses (i.e. 'simple pasts') we will employ the term 'general'. General present tenses are constructions (old imperfectives) which have lost their progressive-continuous sense. Simple past tenses, however, are an entirely distinct phenomenon - these are pasts which offer both imperfective and perfective uses, or which are not aspectually marked. Additionally it should be noted that highly advanced present tenses may undergo a further evolution, developing (by reduction of their semantic potentials) into futures and subjunctives (Bybee et al. 1994: 230-236, 274-278; Haspelmath 1998: 41-45).

2 See for example, the development of the Icelandic progressive past that has become admissible in past perfective contexts in the modern colloquial language: hann var að koma 'he came (lit. he was coming)' (see also Comrie 1976). 
property of the NomKAD constitutes an intermediate-stage between an archetypal ongoing progressive-continuous class and a prototypical iterative category. On the one hand, as an iterative aspect, the formation introduces activities that occur frequently and that are not presently ongoing. On the other hand, as a progressive-continuous gram, it portrays the iteration as a collection of independent progressive and continuous events or situations. Moreover, in less common instances, the NomKAD form may convey a standard iterative sense of frequently repeated activities. This behavior, thus, shows a further development of this construction along the imperfective cline. Additionally, the locution may infrequently be used in order to express customary situations and actions which span large periods of time, providing yet further advancement on the path. It should be noted that both in the iterative and habitual functions, the nuance of current ongoing-ness is unavailable or, at least, not compulsory. The use of the NomKAD expression in the sense of an inclusive perfect provides a further case where the duration of an action or activity is in focus while the current ongoing-ness is secondary. ${ }^{3}$ This function is clearly related to durative and habitual uses and to the fact that the formation can express activities that hold for or span larger portions of time. In these instances, however, the duration does not only include the present reference but - as in many languages, e.g. Polish, German or Spanish - may likewise involve the portion of time which cognitively belongs to the past time sphere: from this, the sense of a durative present in the function of an inclusive perfect emerges. Finally, it must be observed that the NomKAD form is not used as an expression of gnomic truths. If the form is employed within a past time frame, its force is analogical and, as expected, it never indicates past perfective (either punctual or global) events.

Consequently, we may define the formation as a young imperfective diachrony: a) the progressive and iterative-progressive domains are prototypical; b) continuous and iterativecontinuous domains are available only for a few verbs; c) iterative and habitual senses are perceivable, albeit far from being common; d) the gnomic sense fails to be available; and e) the majority of non-dynamic predicates (with the exception of some situational roots) acquires an ingressive (and thus dynamic) reading in this construction. The entire semantic potential of the NomKAD form can be mapped by employing the chaining based upon the imperfective path in the following manner:

roots

meaning extensions

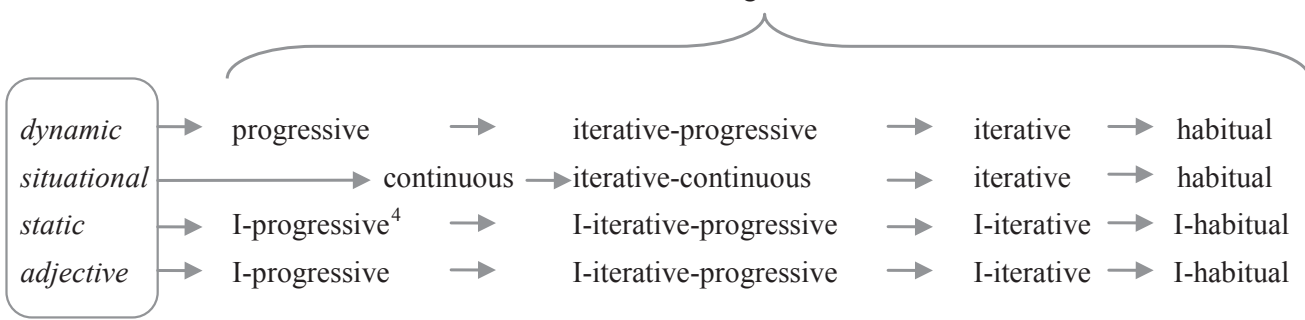

Figure 2: Model of the semantic space of the NomKAD ${ }^{5}$

3 However, the nuance of ongoing-ness in such examples is more palpable than in the habitual and iterative uses. The action or situation is portrayed as holding in an uninterrupted manner from a given point in the past to the present moment.

4 The abbreviation 'I' in I-progressive and I-iterative-progressive stands for 'ingressive'.

5 In the model, for the sake of simplicity, we ignore the sense of durative and, especially its variant, the 'inclusive perfect' (a type of duration which includes the present sphere and a part of the past time sphere as well). 


\section{Corroborating the map}

Having described and modeled the meaning of the NomKAD construction, we will examine the structure of this formation. ${ }^{6}$ As already explained, the mapping of the semantic potential based upon a synchronic review of senses and typological diachronic universals is a plausible hypothesis. Its probability is certainly high (cf. Heine 1997: 10) but without some "proofs" it is nothing more than a postulation. Whenever possible, it should be corroborated by diachronic proofs of which the identification of the input locution is a crucial one. When direct diachronic evidence is scarce - just like in Basse Mandinka where there are no texts from the 19th and 18th centuries - the identification of this original source consists of relating the form of a construction to its meaning: more specifically, structural properties of a gram are required to be cognitively consistent with the posited path and point to an input expression that would motivate the entire path.

\subsection{Structural properties}

As previously mentioned, the NomKAD formation is built on the predicator be (in negative te), a verbal noun derived from the underlying verb and the postposition kay 'at'. It is important to observe that the construction employs the non-verbal predicator be (in negative te) to link the subject (either pronominal or nominal) and the predicate (a verbal noun introduced by the postposition $\mathrm{kal}$ ). In Basse Mandinka, the entity be is typically used in locative expressions (cf. examples 1a-b). However, it does not appear in identifications or definitions; in such instances $m u$ is regularly found (Nte mu tubaaloo le ti 'I am European (Western white man') or Mandinkoo le mu 'He is a Mandinka'.

(1) a.

A be suwo kono
he be home in
'He is at home.'

b.

Bukoo be taabuloo kay
book be table on
'The book is on the table.'

As already explained, the idea of an activity is regularly expressed by a verbal noun an entity which presents the action or situation conveyed by a corresponding verbal form as a nominal concept, e.g. bori 'run' > boroo 'running, a run' taama 'to walk, to travel' >

The durative and durative-inclusive senses should be imagined as forming a parallel extension to the development from progressivity to habituality. While the evolution [progressive / continuous $>$ iterative-progressive $>$ iterative $>$ habitual $>$ gnomic] involves a weakening of the idea of ongoingness and an increase of the frequency and typicality of an activity and, as a result, the expansion of its temporal validity, the change from progressive or continuous to durative (and subsequently to habitual) directly consists of the expansion of the temporal span of an action or situation, i.e. from here-and-now to "a now" which gradually becomes wider.

6 It shall be noted that under the term 'structural', we understand any property which is not related to the verbal semantics of tense, aspect, taxis and mood. Most of them concern morphosyntactic and functional properties: for instance, arrangement of constituents, issue of transitivity, syntactic status of the constituents (object, complement, etc.) and taxonomical categorization of the components of the periphrasis as determined parts of speech (nouns, verbs, adpositions). 
taamoo 'travelling, a travel', a domo 'to eat' > domoroo 'eating, food', a tabi 'to cook' > tabiroo 'cooking' (cf. examples $2 \mathrm{a}-\mathrm{d}$ below). ${ }^{7}$

(2) a.

A be boroo kay
he be running at
'He is running.'

b. A be tamoo kay

he be travelling at

'He is travelling.'

c. A be domoroo kay

he be eating at

'He is eating.'

d. A be tabiroo kay

he be cooking at

'He is cooking.'

An interesting property of the Nominal KAD formation - clearly related to its nominal nature - is the fact that this locution may be employed with no overt "direct object" yet preserve the active character (as will be explained below, this entity is not a direct object properly speaking - it is a direct object of the infinitive from which the verbal noun has been derived). In Basse Mandinka, transitive verbs when used without an overt direct object regularly receive an intransitive and/or passive reading. This means that in order to "keep" a transitive verb (e.g. a safee 'to write') active, the direct object must be expressed (e.g. A be a safee kay 'He is writing it'). In the contrary case, the sense is passive (e.g. A be safee kay 'It is being written'). This rule does not apply to the NomKAD gram which maintains an active value of transitive verbs although a direct object of the underlying infinitive fails to be explicitly provided (cf. $3 \mathrm{~b}$ where the object yiroolu from example $3 \mathrm{a}$ is unexpressed but the construction still remains active).

(3) a. Ì be yiroolu tutoo/tuturoo kan
they be trees planting
'They are planting trees.'
b. İ be tuturoo kay
they be planting at
'They are planting.'

7 The rules of derivation of verbal nouns in Basse Mandinka and their use in determined syntactic environments (e.g. with or without direct objects) are rather complex (for details, see Andrason 2012a). For the purpose of our research, two general facts should be acknowledged. Most commonly, intransitive verbs derive one verbal noun, by adding the suffix - $o$ to the verbal stem. This suffix may subsequently coalesce with the last vocalic element, yielding a frequent ending -oo (e.g. diyaати 'talk' > diyaатоo 'talking; other results of the incorporation of the -o may be -ewo, -iyo or -uwo). On the other hand, originally transitive verbs normally allow the formation of two verbal nouns. One is "short" in $-o$ and follows the principles explained above when describing the derivation of verbal nouns from intransitive predicates (e.g. a sene 'farm' > senoo 'farming' or a borindi 'drive' > borindoo 'driving'). The other is "long" and displays endings in -roo, e.g. a sene 'farm' > seneroo 'farming', a borindi 'drive' > borindiroo 'driving'. There is, however, a group of transitive verbs which possess only one verbal noun

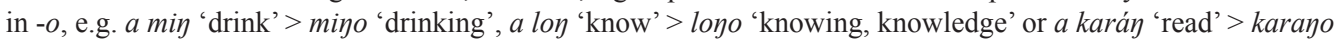
'reading'. 
The invariably active nature of transitive verbs means that the Nominal KAD gram does not generate passive uses. Hence, the sentence quoted below cannot receive a passive reading although the direct object of an underlying transitive verb (i.e. a verb from which the verbal noun has been derived) is left unexpressed. This does not mean that the phrase is not per se incorrect. It may be used in an active sense with a rather odd meaning of 'The trees are cultivating (i.e. the trees are doing the cultivation)'.

$$
\begin{aligned}
& \text { *Yiroolu be senoo / seneroo kan } \\
& \text { trees be cultivating at a being cultivated.' } \\
& \text { 'Intended meaning: Trees are be }
\end{aligned}
$$

It should be noted that the element that corresponds to a direct object of the underlying infinitive (and that, when translated into Indo-European languages, usually appears as a direct object of a transitive verb) is analyzed as a complement of the nominal entity, i.e. of the verbal noun - it forms a nominal phrase whose head is the verbal noun. This complement determines the verbal noun, standing in a broadly understood genitival relation. It is important to observe that such complements may be nominal (definite with -o (cf. 5a), determined by other attributive entities $(5 \mathrm{~b})$ or plural $(5 \mathrm{c}))$ as well as pronominal $(5 \mathrm{~d})$. In all of such cases, the entities yiroo, yiroo niy or yiroolu are complements of the noun (head of the nominal phrase) and the pronoun $a$ corresponds to a possessive pronoun (compare a baamaa 'his father').

(5) a.

M be yiroo seneroo kay
I be tree cultivating at
'I am cultivating a tree.'

b. $\mathrm{M}$ be yiroo nin seneroo kay

I be tree this cultivating at

'I am cultivating the/this tree.'

c. $\mathrm{M}$ be yiroo ninnu seneroo kay

I be tree these cultivating at

'I am cultivating $g$ these trees.'

d. $M$ be a seneroo kay

I be its cultivating at

'I am cultivating it.'

This "genitival" relation between the verbal noun and its nominal complement (and thus the status of a complement, instead of a direct object) may be better perceived in two other structural varieties of the NomKAD construction. Thus far (both in this section and in the previously published PART 1 of the study), we have focused on the most common variety used in Basse and its neighborhood. This type includes underlying intransitive verbs (me be siinoo $\mathrm{ka \eta}$ ) and transitive verbs without or with its object ( $m$ be saferoo $\mathrm{kay}$ and $m$ be a safeeroo $\mathrm{ka \eta}$ ). Underlying verbs with objects, however, can appear in two further types of the NomKAD construction.

In the one of them, the nominal complement is employed in its bare stem shape and the complex [noun + verbal noun] is classified as a compound noun (most commonly, even written together) e.g. yiritutoo 'tree-planting / planting of tree(s)' (cf. example 6, below; see already Creissels 1983). In this type of the NomKAD form, the verbal noun constitutes 
a multifaceted - but yet single - purely nominal concept. Compound nouns are extremely common in Basse Mandinka and this class of compounds does not differ from words such as bendulaa 'meeting place' (bey 'meeting' + dulaa 'place') or duwaañikundaa 'department of tolls' (duwaañi 'toll' + kundaa 'department') in which the first element always appears in its bare stem form. ${ }^{8}$ This formation also has locative ('be in the midst of [doing] something') or busy ('be busy with [doing] something') connotations.

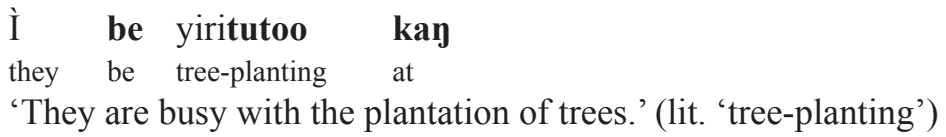

The other type of the NomKAD form employs forms of nouns in - $o$, including plurals, or pronouns (just like the "regular" type described thus far does) but links them to the verbal nouns by means of the postposition la 'of' (see example 7a-c, below). Likewise in this locution, the status of the verbal noun is clearly nominal because the chain yiroo la seneroo can only be interpreted as a nominal chain: 'planting of a/the tree' and constitutes a clear parallel to genitive chains such as dindiyo la bukoo 'the book of the child' or a la bukoo 'his book (i.e. the book of him'). In verbal phrases, the noun or pronoun with la can never stand between a predicator be and a verb (cf. 7d). Once more, this fully nominal expression offers quite evident locative and busy readings. In contrast with the bare stem ( $m$ be yiritutoo $\mathrm{kay}$ ) and la varieties ( $m$ be yiroolu la tutoo $\mathrm{kay}$ ), the locative or busy interpretation of the "regular" NomKAD type ( $m$ be yiroolu tutoo kay) is less evident and, from a semantic perspective, this formation - as already explained in the previous article - seems to be wholly equivalent to the verbal KAD form. ${ }^{9}$

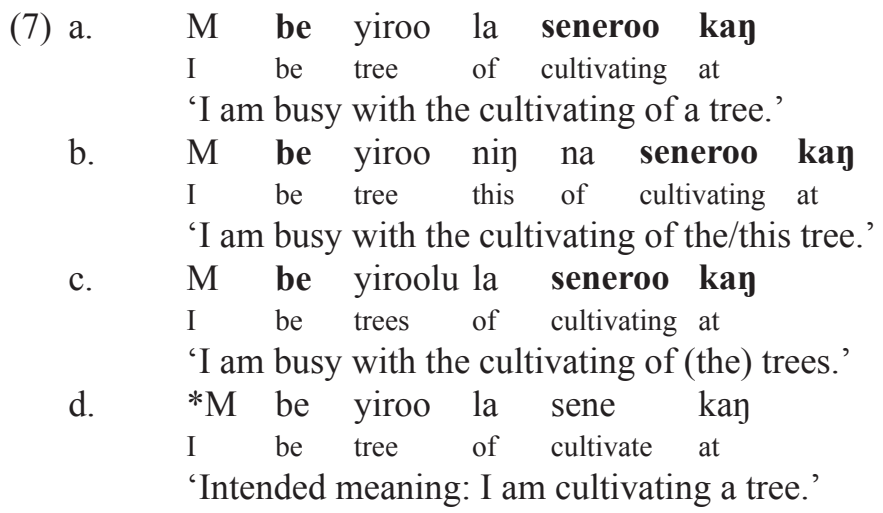

8 Inversely, this means that this variety of the NomKAD cannot be employed if the nominal complement of the verbal noun in definite or plural, or if it is a pronoun.

9 In fact, in case of intransitive and active transitive roots with overt objects of the underlying verb, the two constructions are structurally quite similar. The only distinction is the definite - $o$ ending on the verbal noun in the NomKAD construction. However, if the verb end in a -oo (siinoo) or -aa (bataa) the verbal and nominal KAD formations are identical. (Very infrequently, verbal nouns derived from the roots in - aa show a different tone than the underlying verbs. This is, however, not consistent and most commonly verbs in - $a a$ and their verbal nouns are undistinguishable.) 


\subsection{Relating the structural properties to the map}

Structural properties show that the NomKAD periphrasis should be understood as, at least originally, a nominal locative form. First, the nominal character of the formation is evident due to the following traits: a) its "core" entity is constituted by a verbal noun; b) the relation between the verbal noun and its complement is genitival: by juxtaposition (yiroo tutoo), by incorporation (compound nouns yiritutoo) or by means of the postposition la (yiroo la tutoo); c) the entity which corresponds to the object of the underlying verb (ka yiroo tutu 'to plant a tree') constitutes a complement of the head of a nominal clause (the verbal noun) in the NomKAD locution. By doing so, the formation need not to comply with certain rules which are obligatory for fully verbal grams. To be exact, the imperative concerning the presence and/or absence of overt objects of transitive roots is not respected: a) an entity which corresponds to the object of the underlying transitive verb can be omitted although the construction will still preserve its active character; b) inversely, the lack of an item which corresponds to the object of a verb from which the verbal noun has been derived does not entitle de-transitive and/or passive readings. As a result of this behavior (i.e. because of failing to fulfilling the above-mentioned principles, otherwise compulsory for proper verbal entities), the NomKAD cannot derive de-transitive or passive uses of transitive roots: in all such cases, the construction is invariably active. This morphosyntactic behavior again makes explicitly patent the nominal character of the NomKAD form.

Second, as for the locative components, the construction employs the most prototypical locative non-verbal predicator in the Mandinka language, viz. be, which links the subject to the adpositional predicate composed by the postposition kay and a verbal noun that expresses a given activity.

Thus, the formation displays an underlying form which corresponds to the following literal expression: to be at the act of performing something. This structure clearly matches entirely nominal locative-busy locutions, common in Basse Mandinka, such as those in $8 \mathrm{a}$ and $8 \mathrm{~b}$ below. In these phrases, the periphrasis constructed by the entity be and the postposition kay employs purely nominal segments as postpositional complements, i.e. the interrogative pronoun munne 'what?' and the pronoun of the $3^{\text {rd }}$ person singular $a$ 'he, she, it'. Thus, the NomKAD formation differs from these types of locutions exclusively in the fact that, instead of a pronoun, it uses a verbal noun. This type of a locative non-verbal adpositional predicative construction (BE AT SOMETHING) most probably constitutes the original lexically transparent input from which the NomKAD form has emerged.

(8) a.

I be munne kan?
you be what at

'What are you busy with? / What are you doing?' (Andrason 2012b: 40)

b. $M$ be a kay

I be it at

'I am busy with it / I am doing it' (Gamble 1987: 39; cf. the Spanish correspondence Estoy en ello 'I am at it')

It is highly relevant to acknowledge that such locative nominal, frequently adpositional, constructions (i.e. BE AT SOMETHING) constitute an extremely productive source of grams which develop along the imperfective path. 
Typological studies teach us that the original value of progressives commonly corresponds to the following idea: "the subject is located (spatially) in the midst of doing something (i.e. in the midst of an activity at reference time)" (Bybee et al. 1994: 136). This means that progressives are often derived from locative categories where the locative connotations of the subject and its activity are in focus (cf. Anderson 1973; Traugott 1978; Bybee et al. 1994: 137; Ebert 2000: 607). In such original formations, the item that makes reference to the location typically is identical to positional copulas or other "be-like" entities (including postural verbs and non-verbal items). Furthermore, the idea of a given activity is commonly conveyed by verbal nouns or gerunds (Bybee et al. 1994: 128-131; Ebert 2000: 607). Thus, the form of a main verb - i.e. of the element that identifies the type of action - is usually nominal. Subsequently, the locative sense 'be in place of doing' gives rise to a busy sense and, later, to a prototypical progressive value 'be at doing' (Bybee et al. 1994: 130; Ebert 2000: 607; Bertinetto et al. 2000: 540). What links together most of progressive constructions is the fact that they originate from a locative periphrasis that presents the subjects as literary sitting, being situated, or being occupied with performing an action. Only later are progressive, continuous and finally iterative and habitual values incorporated (Bertinetto et al. 2000: 540; Dahl 2000).

Consequently, the structural properties of the NomKAD are fully consistent with the most plausible source for the imperfective cline. Its locative and nominal character suggests that the formation derived from an original locative expression. This locative value (additionally accompanied by busy-meaning) is clearly perceivable in the purely nominal matrices of the NomKAD form (cf. sentences in 8, above) as well as in two subtypes of this construction: i.e. in cases where the underlying object is incorporated in its bare stem form to the verbal noun (cf. example 6, above) and in cases where it is linked to the verbal noun by means of the postposition la (cf. examples $7 \mathrm{a}-\mathrm{c}$, above).

Summa sumarum, the structure of the NomKAD formation is fully harmonious with the path mapping of its semantic potential and confirms the chaining based upon the inventory of senses. All the formal traits and the morphosyntactic behavior of the gram validate the understanding of the NomKAD locution as a prototypical young imperfective form: it derives from a locative construction built on a nominal entity (verbal noun) and a postural item (the predicator be). Such an input - and thus the form of the NomKAD construction in Basse Mandinka - is entirely compatible with all the senses conveyed by this locution, because it constitutes its semantically transparent and cognitively plausible source.

\section{Conclusion}

In this series of two articles we have demonstrated that the semantic potential of the NomKAD construction can be modeled as an initial portion of the imperfective path. The inventory of senses synchronically offered by this form in Basse Mandinka enabled us to match the components of the meaning of the NomKAD with various sections of the imperfective cline, i.e. with the stages of progressivity, continuity, iterative-progressivity, iterativity and habituality, as well as (inclusive-)durativity. It was also observed that the most prototypical uses corresponded to the initial domain of a progressive aspect, while continuous, 
progressive-iterative, iterative, and habitual senses (which correspond to more advanced parts of the trajectory) were said to either be confined to a few verbs or to less frequent cases.

This cognitive model - derived from synchronic evidence and certain typological universals - has subsequently been confirmed by the formal traits of the NomKAD construction. To be exact, we have demonstrated that the structural and morphosyntactic properties of this locution (especially, the presence of a locative component be and the nominal character of the gram which frees it from observing otherwise compulsory rules concerning transitive and de-transitive/passive constructions) are fully compatible with the proposed path mapping. All the formal characteristics jointly suggest that the locution emerged from a locative nominal adpositional periphrasis, one of the most prototypical sources of grams evolving along the imperfective cline.

Although the present study has reached its main objective and offered a semantic classification of the NomKAD form within a cognitive-grammaticalization framework, it has certainly not answered all the questions concerning the meaning of this construction. First of all, the proposed path model is typically qualitative (cf. Gries 2006: 4-5): all the senses were treated as equally important and each stage on the cline received an identical weight in the map. We only mentioned that certain values were more frequent (and hence more prototypical) while others were uncommon (and thus peripheral). In order to render our model more precise and accurate, a quantitative corpus study is necessary. This analysis would determine an exact distribution and frequency of the components of the semantic potential of the NomKAD form and thus of the elements of the map. Logically, this study will constitute one of the research activities of the author in the future.

\section{References}

Anderson, Lloyd. 1973. An essay concerning aspect: some considerations of a general character arising from the Abbé Darrigol's analysis of the Basque verb. The Hague: Mouton.

Andrason, Alexander. 2012a. The KAD verbal form in Basse Mandinka - structure and meaning. Studia Linguistica Universitatis Jagellonicae Cracoviensis 129. 35-48.

Andrason, Alexander. 2012b. The structure and meaning of the Nominal BE...LA "tense" in Basse Mandinka. The Annals of Ovidius University of Constanţa 32(1). 21-38.

Bertinetto, Pier Marco \& Ebert, Karen \& De Groot, Casper. 2000. The progressive in Europe. In Dahl, Östen (ed.), Tense and aspect in the languages of Europe, 517-558. Berlin-New York: Mouton de Gruyter.

Bertinetto, Pier Marco \& Lenci, Alessandro. 2010. Iterativity vs. habituality (and gnomic imperfectivity). Quaderni del Laboratorio di Linguistica 9(1). 1-46.

Bybee, Joan \& Perkins, Revere \& Pagliuca, William. 1994. The evolution of grammar. Chicago: The University of Chicago Press.

Comrie, Bernard. 1976. Aspect. Cambridge: Cambridge University Press.

Creissels, Denis. 1983. Eléments de grammaire de la langue mandinka. Grenoble: ELLUG.

Dahl, Östen (ed.). 2000. Tense and aspect in the languages of Europe. Berlin-New York: Mouton de Gruyter.

Ebert, Karen. 2000. Progressive markers in Germanic languages. In Dahl, Östen (ed.), Tense and aspect in the languages of Europe, 605-653. Berlin-New York: Mouton de Gruyter.

Gamble, David. 1987. Elementary Mandinka (Gambian Studies 20). San Francisco: Gamble.

Greenberg, Joseph \& Ferguson, Charles \& Moravcsik, Edith (eds.). 1978. Universals of human language. Stanford: Stanford University Press.

Gries, Stefan. 2006. Introduction. In Gries, Stefan \& Stefanowitsch, Anatol, Corpora in cognitive linguistics, 1-17. Berlin-New York: Mouton de Gruyter. 
Gries, Stefan \& Stefanowitsch, Anatol. 2006. Corpora in cognitive linguistics. Berlin-New York: Mouton de Gruyter.

Hamlyn, Willaim. 1935. A short study of the Western Mandinka language. London: The Crown Agents for the Colonies.

Haspelmath, Martin. 1998. The semantic development of old presents: New futures and subjunctives without grammaticalization. Diachronica 15(1). 29-62.

Heine, Bernd. 1997. Cognitive foundations of grammar. Oxford: Oxford University Press.

Marchese, Lynell. 1986. Tense/Aspect and the Development of Auxiliaries in the Kru Language Family. Arlington: SIL-University of Texas Press.

Traugott, Elisabeth Closs. 1978. On the expression of spatio-temporal relations in language. In Greenberg, Joseph \& Ferguson, Charles \& Moravcsik, Edith (eds.), Universals of human language, 369-400. Stanford: Stanford University Press. 